\title{
The Effect of Exposure on Chinese Learners' Processing of English Wh-movement Sentences
}

\author{
Hulin Ren ${ }^{1}$ \\ ${ }^{1}$ Department of English Language, North China Electric Power University, Beijing, 102206, China \\ Correspondence: Hulin Ren, Department of English Language, North China Electric Power University, Beinong \\ Road 2, Changping District, Beijing, 102206, China. Tel: 86-10-6177-2215. E-mail: hulinr@yahoo.com.cn \\ Received: March 16, 2013 \\ Accepted: April 6, 2013 \\ Online Published: April 15, 2013 \\ doi:10.5430/elr.v2n1p64 \\ URL: http://dx.doi.org/10.5430/elr.v2n1p64
}

It was supported by the Project of Oversea Scholar Fund, Ministry of Education, China

\begin{abstract}
The study is to examine the effect of exposure on Chinese learners' differences in the comprehension of three types of wh-movement structural sentences in English, such as Who did the boy think pinched the goat? Chinese learners with 10 years' (group 1) and 5 years' (group 2) amount of formal exposure with English and one control group with 10 years exposure to English participated both off-line and on-line comprehension tests. Findings indicated that the two Chinese groups had the same comprehension accuracy as the control group, but differ in reading times. In spite of having longer comprehension times, group 2 got relatively lower comprehension scores, indicating that there is a strong correlation between Chinese learners' response times and comprehension accuracy and the amount of formal exposure. These findings are discussed regarding the role of formal amount of exposure in complex English sentence processing, and conclusions are drawn on Chinese learners' comprehension of complex English syntactic structures.
\end{abstract}

Keywords: Exposure, $W h$-movement relative clause, Sentence processing

\section{Introduction}

Recently the exposure-based account, which basically claims that sentence processing is related to the amount or frequency of a language (e.g. Frenck-Mestre, 2002; Cuetos et al., 1996), is one common approach to account for learners' differences in sentence processing performance. By this account, syntactic priming occurs when processing of a target sentence is facilitated following processing of a prime sentence that has the same syntactic structure (Bock, 1986: 355). Substantial body of evidence shows that individual parsing decisions are influenced in some way by prior exposure or contact with comparable strings or structures (e.g. Mitchell, et al, 1995).

In second language (L2) study, it is generally accepted that most non-native speakers are clearly different from a native speaker even after a substantial amount of exposure or instruction of a given syntactic structure, such great amount of exposure may usually take place in a classroom-based formal teaching setting, where L2 learners favor explicit learning strategy (e.g. memorization and retrieval strategies). Hernandez et al. (1996) confirmed sentential priming, which is characterized by McDonough and Mackey (Note 1) (2008) as a speaker tending to produce a recent-encountered sentence structure, shows automatic and controlled effects (i.e. easily affected by the priming) with Spanish-English bilinguals. The automatic effects can be explained in terms of experience-based sentence parser, namely, the frequency of a structure and processing performance are correlated: more frequent structures are easier to process, as the processor is more likely to have encountered them before, and choose them more readily as the correct analysis. Similarly, Shin and Christianson (2012) found that L2 learners, after the structural priming session, showed an overall increase in target structure production, from which they assume that structural priming is one type of automatizing or fine-tuning procedural knowledge, where L2 learners may acquire by repeating the modeled form in new sentences and undergoing practice.

Contrary to the findings mentioned above, Lee (2009) found that Korean learners of English made judgment on grammaticality of subject $w h$-questions faster and more accurate, compared with the judgment of object wh-questions in English, and the learners tended to confuse object and subject wh-questions. Due to the distance between the $w h$-word and the gap is shorter, Lee explains, English subject $w h$-questions are easily processed and therefore consumes less capacity of working memory in the real time processing of subject than in object 
wh-questions. The result justifies L2 learners' comprehension of English relative clause sentences may be perceived from capacity of working memory.

The contradictory findings suggest that L2 learners' comprehension performance may be either related to instruction amount or capacity of working memory. Therefore, it is significant to further explore the nature of L2 learners' differences in sentence processing, mainly in complex sentence processing. In accordance with the exposure-based account, one may expect to see such effects in the comprehension of complex wh-movement sentences across L2 learners who had received different amounts of instruction. The current study sets out to examine the amount of exposure (Note 2) (explicit instruction) on Chinese learners' processing ability by comparing their comprehension accuracy and response times in comprehending English wh-related relative clause sentences. In the following, an experiment is fully described to report on the processing of the English relative clause sentences by Chinese learners, followed by the results and discussion. Finally it concludes with the role of exposure in comprehending the English sentences.

\section{The present experiment}

\subsection{Aim}

The experiment aims to examine the exposure-related differences in the ability to comprehend wh-related English relative clause sentences by Chinese learners of L2 English who have received different formal schooling of English as a L2. The ability here is operationalized measuring the accuracy and response times in the comprehension of the sentences.

\subsection{Design}

\subsubsection{Subjects}

Two experimental groups of Chinese learners of English are studied. Group 1 consists of 20 Chinese learners of English. They were first year students who were pursuing a Master's degree in non-English related subjects at North China Electric Power University. Their average age was 28 years old, 10 female and 10 male. All of the subjects in this group had never been to English-speaking countries; but they all received formal explicit instruction of English grammar. They had received 10 years of formal schooling on English as a L2.

Group 2 consists of 20 Chinese learners of English, 8 male and 12 female from Beijing Number 20 School. They had received formal schooling of English as a L2 for 5 years. They began their formal English instruction at the age of 11 . Their mean age was 17 years old. All three groups had not received formal instruction of other languages except Chinese and English.

The control group is 20 well-educated native-English speakers from UK, who had good knowledge of English-related subjects. When testing is conducted, they are oral English teachers at North China Electric Power and Beijing Normal University, China. The mean age of this group is 27 years old. Biographical information for the four groups is presented in table 1. Subjects in all four groups did not know the purpose of the experiment.

Table 1. Subject biographical information $(\mathrm{N}=20)$

\begin{tabular}{cccc}
\hline \hline Biographical information & Group 1 & Group 2 & Control group \\
& M (SD) & M (SD) & M (SD) \\
\hline \hline Age & $28(3.20)$ & $17(0.75)$ & $27(2.18)$ \\
Beginning age of formal English instruction & $11(0.51)$ & $11(0.72)$ & N/A \\
Formal years of English instruction & $10(0.56)$ & $5(0.83)$ & N/A \\
Dominant language & Chinese & Chinese & English \\
\hline
\end{tabular}

\subsubsection{Material}

The material for the experiment includes three types of $w h$-movement structural sentences: two types of sentences in English, i.e. subject and object $w h$-question English sentences, such as sentence (1) and (2) below, and one typical complex $w h$-movement structure in English, such as in sentence (3). To comprehend subject and object $w h$-question English sentences, one has to identify real subject or object of the given sentences. For example, to comprehend sentence (2), it is important to correctly recognize the subject of the sentence and the syntactic role of who. The complex wh-movement structure in English involves movement over subjects and verbs, namely this complex structure involves a centre-embedded relative clause. More exposed L2 learners will perform better in the comprehension of this type of sentence, as such a recursive operation is supposed to be equipped with the L2 English learners, i.e. learners with more exposure will have less difficulty in comprehension than those with less amount of exposure to structure in question (Juffs, 2006). 
(1) Who did the man think pinched the pig? (subject wh-question)

(2) Who did the man think the rabbit pinched? (object wh-question)

(3) Who did the man that the clerk had pleased speak to in a room?

\subsubsection{Procedure}

The off-line experiment followed Ren's (2009) procedure, the less-exposed subjects were given written versions of all the test sentences and checked for any potential problems in literacy that might disturb the comprehension test. After doing this, all subjects (i.e. the two experimental groups with different amount of exposure) were required to read the sentences one by one and were told that they were allowed to backtrack whenever necessary so that they could process the sentences at their own pace. After studying the sentences to their satisfaction, the subjects were then asked to answer questions about the sentences. Questions about the sentences were read out by a native English speaker. If learners had problems in understanding the questions, the questions would be repeated as many times as was necessary until they fully understood them. The same procedure applied to the control group.

The on-line comprehension test was conducted three weeks after the off-line experiment. The same subjects were instructed to process the 20 English sentences. The tasks were conducted by using laptop individually to the experimental subjects. To start, participants were instructed to know the instructions displayed on the screen first, they were allowed to ask teachers to explain anything they were not clear. After knowing the instructions clearly, participants began to practice to guarantee that they had good command of using the response box to show comprehension material.

In what follows was the timed computer-administered comprehension, which was the actual online formal test. Participants carried on their tests by using their response boxes. All the testing sentences had four comprehension questions ready to answer. The comprehension questions for each sentence were shown one by one by using the response box button. If the last response box button clicked, a new test sentence was immediately shown on the screen. The sentences were displayed one full sentence at a time (the stimuli were not displayed in the normal fashion of segmentation because a pilot study had showed that the less-exposed subjects might get lost with this procedure), and followed by questions. The presentation of the whole material and the comprehension process were recorded by the Superlab Pro 4.0 software. The whole test took 25 minutes.

\section{Results and discussion}

Results of the experiment are focused on effects of groups, structures, and questions in the comprehension performance. Following each of these sections is a general discussion of the results.

\subsection{Groups}

Between-groups comparisons were computed by comparing the overall accuracy scores for the entire test, this was because that, according to Hopp (2006), accuracy scores could have direct and accurate observation of the comprehension performance. The overall accuracy consists of 10 points, among which question 1 (key question) was given 5 points (if correct); question 2 was given 3 points; question 3 was given 1 point and question 4 was given 1 point as well. Group 1 obtained the highest comprehension scores (95\%), followed by the control group (92\%) and group $2(82 \%)$. ANOVA analysis shows there are no significant group differences in the total mean accuracy $(\mathrm{p}>0.05)$. Three further pairwise tests show that group 1 and group 2 had great differences $(p<0.01)$, so is the same between control group and group $2(\mathrm{p}<0.01)$. The results give support to the exposure account that amount of exposure is related to the ability in processing skills, indicating that amount of explicit instruction or formal schooling develops Chinese learners' syntactic knowledge in processing the complex English sentences. The main effect of groups for the key questions is significant $(\mathrm{F}(2,26)=6.15, \mathrm{p}<0.01)$. A pairwise test shows, for the key questions, the only significant difference is found between groups $1 \& 2(\mathrm{p}<0.001)$. There is a great difference between group 1, group 2 and the control group when data from all four comprehension questions are analysed, which reaches statistical significance $(\mathrm{p}>0.05)$. Group 1 is significantly more consistent than the control group, but not group 2. It appears that Chinese learners vary in their processing abilities: group 1 outperformed native English speakers, group 2 was lower than the native English speakers.

The effect of groups is generally compatible with the exposure-based approach, in the sense that comprehension is found to be related to the amount of exposure. This is evidenced from the fact that group 1 did better comprehension performance than group 2, where more instructed Chinese learners of English (of course with more exposure to English) have better performance in comprehension accuracy than the less-instructed learners. However, group 1 outperformed control group in the comprehension test. This result is not in agreement with the common assumption 
that L2 learners never reach native-like proficiency, though the test sentences like sentence (3) are highly unusual in ordinary discourse.

Given that non-native processing may be delaying or inefficiencies compared to native processing, results in this experiment indicate that large amount of exposed Chinese learners do not show a reduced sensitivity to (at least some kinds of) syntactic information in their parsing, which is in contrast to the claim by Felser and Roberts (2007) that non-native parsing has a reduced sensitivity to syntactic information.

Within-groups comparisons on overall accuracy scores for the entire test are slight ( $p>0.05)$, indicating participants in each of the three groups display no great differences in comprehension accuracy. The same applies to the questions to be tested, where there is again no significant difference in performance. Significant differences in comprehension test on different sentence types were observed, which is described below.

\subsection{Structures}

The percentage of correct responses for sentence structures is given in table 2, which shows that $w h$-related subject sentences $(90 \%)$ are more difficult to understand than object relative clause sentences $(97 \%)$, the wh-movement sentences are the most difficult to comprehend (with a total mean accuracy of 63.0\%).

ANOVA analysis shows that different structures have significant differences in comprehension scores $(\mathrm{F}(3,26)=$ $7.06, p<0.001)$. Groups and structures are closely interacted $(\mathrm{p}<0.001)$. This greatest effect can be seen on group 2 $(p<0.001)$, which obtains only $48.4 \%$ accuracy scores for the complex NP structure. There is also an effect of structures on group 1 and $2(\mathrm{p}<0.05)$, but no significant effect is observed on the control group $(\mathrm{F}(3,26)=1.69, \mathrm{p}=$ $0.15)$. This finding suggests that the two groups of non-natives are more consistent than the control group. Subjects' responses to each of the structures is described in turn, first relative clause structures, and then complex wh-movement structure.

Table 2. Proportion of correct responses to the sentence structures

\begin{tabular}{lccccccccc}
\hline \hline Group & \multicolumn{2}{c}{$\begin{array}{l}\text { Subject relative } \\
\text { clause sentences }\end{array}$} & \multicolumn{2}{c}{$\begin{array}{l}\text { Object relative } \\
\text { clause } \\
\text { sentences }\end{array}$} & $\begin{array}{c}\text { Complex } \\
w h \text {-movement } \\
\text { sentences }\end{array}$ & Overall \\
\hline \hline & $\mathrm{M}$ & $(\mathrm{SD})$ & $\mathrm{M}$ & $(\mathrm{SD})$ & $\mathrm{M}$ & $(\mathrm{SD})$ & $\mathrm{M}$ & $(\mathrm{SD})$ \\
Group 1 & 9.43 & $(1.02)$ & 9.97 & $(0.92)$ & 6.83 & $(1.92)$ & 8.74 & $(1.29)$ \\
Group 2 & 8.24 & $(1.27)$ & 9.24 & $(1.24)$ & 5.02 & $(3.92)$ & 7.50 & $(2.14)$ \\
Control group & 9.40 & $(1.16)$ & 9.95 & $(0.53)$ & 7.05 & $(0.94)$ & 8.80 & $(0.87)$ \\
Total & 9.02 & 1.15 & 9.72 & 0.89 & 6.3 & 2.26 & 8.35 & 1.43 \\
\hline \hline
\end{tabular}

Note: The total score is ten.

Subject relative clause structure: Some interesting findings follow from the subjects' (especially group 2) different responses to questions 1 related to subject relative structure. An example of a complex NP sentence (3), the question, and an answer, are given below.

(3) Who did the girl think pinched the pig? (subject wh-question)

Q What pinched the pig?

A Who did the girl think

Responses to the question fall into three main categories: i) a verbatim response (about 30\% of the answers): this response is to answer question 1 by means of simply repeating the test sentences shown in the sentences above. Subjects who give this response may or may not be able to parse the sentence. ii) Rearrangement (about $45 \%$ of the answers): subjects interchange the constituents by changing the relative clause subject to the end of the sentence. Therefore Who did the girl think pinched the pig becomes The girl think who pinched the pig. Subjects who make this kind of rearrangement are clearly able to parse the sentence since they know to encode a same set of grammatical relations by using alternative configurations, but may be incorrect. iii) Confusion of main predicate constituents (about $25 \%$ of the answers): incorrect responses often involve confusing predicate constituents.

The general pattern of results from subject relative sentences indicates that subjects who failed to comprehend this 
structure seem to have a problem with the form of who + aux + subject + verb + complement clause sequence. Subjects who understood the sentences correctly seem to achieve comprehension in a more rule-governed manner, in the sense that they can shift major constituents in the comprehension test. Group 2 carries out more omissions in the predicate of the top level complement clause than the other two groups (i.e. group 1 and control group), which results in lower accuracy scores in comprehension. The control group seems also to behave in a grammatical rule-governed manner in the test.

Complex $\boldsymbol{w h}$-movement structure: Unexpected findings were obtained from the comprehension accuracy test of the wh-movement structure. As there is no complex wh-movement structure in Chinese, it could therefore be expected that Chinese learners would achieve relatively low accuracy scores in comprehension, at least if L1 affects L2 processing. Surprisingly, the total mean score of this structure is $63.1 \%$, which is lower than that of wh-related relative clause sentences $(90.2 \%$ and $97.2 \%$ ) (see table 2 ). The two experimental groups obtained relatively high mean accuracy scores in comprehension of this structure: group 1 averages $68.3 \%$ and group 2 averages $50.2 \%$, suggesting that they had rather little difficulty with this structure. The native speakers obtained high mean accuracy scores $(70.5 \%)$, indicating that the complex $w h$-movement structure is easier for them too. Possibly it is frequent in natural discourse as $w$ h-related relative clause structure.

The effect of structures suggests that Chinese learners (whether at high-exposed or low-exposed level) have a systematic knowledge of English grammar, but are at a differential level. This pattern of group differences is consistent with the different levels of explicit grammatical knowledge and exposure to English. Group 1, which has more explicit knowledge of English grammar (on account of their linguistic background) and more amount of exposure, seems to have more systematic way in the comprehension of the structure. Group 2, whose explicit grammatical knowledge and exposure are presumably less than that of group 1, ranks the lowest.

Questions: The effect of questions can be seen in table 3, which shows that there are differences in accuracy scores for questions $(\mathrm{p}<0.001)$. (Note 3$)$

Table 3. Question mean accuracy scores (standard deviations in parentheses)

\begin{tabular}{|c|c|c|c|c|c|c|c|c|c|c|c|c|}
\hline \multirow[b]{2}{*}{ Structure } & \multicolumn{4}{|c|}{ Group 1} & \multicolumn{4}{|c|}{ Group 2} & \multicolumn{4}{|c|}{ Control group } \\
\hline & $\begin{array}{c}\mathrm{M} \\
(\mathrm{Q} 1)\end{array}$ & $\begin{array}{c}\mathrm{M} \\
(\mathrm{Q} 2)\end{array}$ & $\begin{array}{c}\mathrm{M} \\
\text { (Q3) }\end{array}$ & $\begin{array}{c}\mathrm{M} \\
(\mathrm{Q} 4)\end{array}$ & $\begin{array}{c}\mathrm{M} \\
(\mathrm{Q} 1)\end{array}$ & $\begin{array}{c}\mathrm{M} \\
(\mathrm{Q} 2)\end{array}$ & $\begin{array}{c}\mathrm{M} \\
\text { (Q3) }\end{array}$ & $\begin{array}{c}\mathrm{M} \\
(\mathrm{Q} 4)\end{array}$ & $\begin{array}{c}\mathrm{M} \\
(\mathrm{Q} 1)\end{array}$ & $\begin{array}{c}\mathrm{M} \\
(\mathrm{Q} 2)\end{array}$ & $\begin{array}{c}\mathrm{M} \\
\text { (Q3) }\end{array}$ & $\begin{array}{c}\mathrm{M} \\
(\mathrm{Q} 4)\end{array}$ \\
\hline $\begin{array}{l}\text { Subject } \\
\text { relative } \\
\text { sentences }\end{array}$ & $\begin{array}{c}4.13 \\
(1.56)\end{array}$ & $\begin{array}{c}1.80 \\
(1.65)\end{array}$ & $\begin{array}{c}.87 \\
(.59)\end{array}$ & $\begin{array}{c}.83 \\
(.45)\end{array}$ & $\begin{array}{c}2.52 \\
(2.14)\end{array}$ & $\begin{array}{c}1.50 \\
(1.35)\end{array}$ & $\begin{array}{c}.43 \\
(.59)\end{array}$ & $\begin{array}{c}.79 \\
(.58)\end{array}$ & $\begin{array}{c}4.43 \\
(1.86)\end{array}$ & $\begin{array}{c}1.50 \\
(1.45)\end{array}$ & $\begin{array}{c}.83 \\
(.56)\end{array}$ & $\begin{array}{l}.83 \\
(.55)\end{array}$ \\
\hline $\begin{array}{l}\text { Object } \\
\text { relative } \\
\text { sentences }\end{array}$ & $\begin{array}{c}4.73 \\
(1.26)\end{array}$ & $\begin{array}{c}1.5 \\
(1.32)\end{array}$ & $\begin{array}{c}.70 \\
(.41)\end{array}$ & $\begin{array}{l}.90 \\
(.61)\end{array}$ & $\begin{array}{c}4.0 \\
(2.27)\end{array}$ & $\begin{array}{c}1.3 \\
(1.46)\end{array}$ & $\begin{array}{c}.57 \\
(.52)\end{array}$ & $\begin{array}{c}.67 \\
(.62)\end{array}$ & $\begin{array}{c}5.0 \\
(.00)\end{array}$ & $\begin{array}{c}1.9 \\
(1.32)\end{array}$ & $\begin{array}{c}.77 \\
(.39)\end{array}$ & $\begin{array}{l}.50 \\
(.61)\end{array}$ \\
\hline $\begin{array}{l}\text { Complex } \\
\text { wh-movement } \\
\text { sentences }\end{array}$ & $\begin{array}{c}4.11 \\
(1.06)\end{array}$ & $\begin{array}{c}1.82 \\
(1.25)\end{array}$ & $\begin{array}{c}.77 \\
(.49)\end{array}$ & $\begin{array}{l}.73 \\
(.35)\end{array}$ & $\begin{array}{c}2.51 \\
(2.04)\end{array}$ & $\begin{array}{c}1.53 \\
(1.25)\end{array}$ & $\begin{array}{c}.33 \\
(.49)\end{array}$ & $\begin{array}{c}.81 \\
(.49)\end{array}$ & $\begin{array}{c}4.33 \\
(1.76)\end{array}$ & $\begin{array}{c}1.45 \\
(1.35)\end{array}$ & $\begin{array}{c}.85 \\
(.46)\end{array}$ & $\begin{array}{l}.84 \\
(.35)\end{array}$ \\
\hline
\end{tabular}

Response times: Supposing that exposure has effects on comprehension performance, the effects should be observed in response times of the participants, comprehension accuracy, or both of the two. In order to examine and compare differences between exposure-related group differences in the online comprehension test, we had statistical analyses on comprehension accuracy and response times. Our rationale is only calculating correct trials of the response time data. Besides, trials exceeding $1000 \mathrm{~ms}$ were not calculated from the groups. This is based on three separate pilot studies with Chinese learners of English. (Note 4 ) This affects approximately $0.4 \%$ of all the responses. To reduce the least possibility of individual outliers, trial response times that are beyond 500 SDs (see table 4 below) are also not calculated from the data set, which affects $1 \%$ of the whole data.

Response time data were divided into two: 1) SRTs, i.e. times from concentrating on studying a fully displayed sentence on the screen to begin answering any questions and 2) QRTs, i.e. times spent answering questions. Mean SRT and QRT (ms) for group differences are listed separately in table 4 and 5 below.

Overall, as can be seen in table 4, native English speakers had the shortest SRTs (3366ms). Least-exposed Chinese learners had the longest times $(6945 \mathrm{~ms})$ and less-exposed Chinese learners were in the middle (5298 ms). A one-way 
ANOVA analysis with factors group, structure and total mean sentence reading times shows that there are significant differences $(\mathrm{F}=29.83, \mathrm{p}<0.001)$, suggesting that there are group differences in SRTs in the comprehension of sentence structure. Groups SRT differences clearly show that the amount of exposure has an effect on RTs. The effect of structures on SRT can also be observed from table 4, which shows questions have effect on comprehension times $(\mathrm{p}<0.05)$.

Table 4. Group mean SRT (ms) (standard deviations in parentheses)

\begin{tabular}{lccc}
\hline \hline & Group 1 & Group 2 & Control group \\
\hline \hline $\begin{array}{l}\text { Subject relative } \\
\text { clause sentences }\end{array}$ & $723(403)$ & $813(419)$ & $705(548)$ \\
$\begin{array}{l}\text { Object relative } \\
\text { clause sentences }\end{array}$ & $617(339)$ & $729(481)$ & $569(369)$ \\
$\begin{array}{l}\text { Complex } \\
\begin{array}{l}w h \text {-movement } \\
\text { sentences }\end{array}\end{array}$ & $819(453)$ & $982(469)$ & $803(478)$ \\
\multicolumn{1}{c}{ Total } & $720(398)$ & $841(456)$ & $692(465)$ \\
\hline \hline
\end{tabular}

Regarding the QRT, table 5 shows that native speakers had the least comprehension times (246 $\mathrm{ms}$ ), followed by least-exposed Chinese learners $(385 \mathrm{~ms})$. Interestingly, the most-exposed Chinese learners had the longest comprehension times $(557 \mathrm{~ms})$. The results show that $\mathrm{L} 2$ sentence processing is slower than $\mathrm{L} 1$ sentence processing.

Table 5. Group mean QRT (ms) (standard deviations in parentheses)

\begin{tabular}{cccc}
\hline \hline & Group 1 & Group 2 & Control group \\
\hline \hline $\begin{array}{c}\text { Subject relative clause } \\
\text { sentences }\end{array}$ & $529(453)$ & $819(484)$ & $390(255)$ \\
$\begin{array}{c}\text { Object relative } \\
\text { clause sentences }\end{array}$ & $397(389)$ & $629(452)$ & $318(219)$ \\
$\begin{array}{c}\text { Complex } \\
w h \text {-movement } \\
\text { sentences }\end{array}$ & $629(493)$ & $979(497)$ & $490(325)$ \\
Total & $518(445)$ & $809(478)$ & $399(266)$ \\
\hline \hline
\end{tabular}

Group effect analysis on QRT shows that the amount of exposure has a marginal effect on comprehension times $(\mathrm{F}=$ 1.07, $\mathrm{p}=0.25$ ). A one-way ANOVA analysis with factors of structures, groups and mean question response times shows that there are significant differences $(\mathrm{F}=12.17, \mathrm{p}<0.001)$. A further analysis of $\mathrm{QRT}$, we can see structures affect comprehension times $(\mathrm{p}<0.05)$.

As our statistical analyses are mainly on mean comprehension accuracy and mean RTs. There might be a potential problem of time-accuracy trade-off. To prevent this happening, we had Pearson correlation analyses on participants' individual mean QRTs and accuracy scores in comprehending the sentences. The results indicated that the experimental subjects did not systematically trade RTs for accuracy, or vice versa, as significant correlation is $\mathrm{p}>0.05$.

\section{General discussion}

The $w h$-related subject and object structures used in the study are common English $w h$-movement constructions, but the complex $w h$-movement structure is relatively less exposed. The $w h$-movement sentences are different in that they do not involve recursion. Based on the fact that English has recursive rules, and that Chinese L2 learners of English with different amount of formal schooling have a different knowledge of English grammar, the more exposed learners should have larger accumulation of structures. One would expect that they have an advantage in comprehension performance. This clearly justifies the exposure-based account for L2 learners in sentence 
processing.

It seems that less-exposed Chinese learners may have less accumulated linguistic resources and therefore are more likely to make little use of available structures in the comprehension performance, which is suggested by Pickering and Branigan (1999). Similarly, exposed Chinese learners with more resources available perform better, as they have presumably experienced more instances of sentences of the appropriate structural form from the amount of formal instruction or exposure. The effect of exposure to relevant instances of particular structures needs to be further investigated.

Besides a possible effect of memory limitations (e.g. Lee, 2009 ), the reason that the less-exposed group failed to comprehend the sentences lies in the fact that they lack of exposure to the syntactic structures, which is consistent with exposure-based account in syntactic competence. On the other hand, the more formal schooling Chinese learners are more accurate, and more consistent across structures. Interestingly, the more-exposed Chinese learners of L2 English display a level of comprehension that outperformed the control group. It appears that Chinese learners' formal schooling on the explicit rules of English grammar is very successful, at least in equipping speakers with the capacity to handle syntactic complexities.

Given that formal schooling may contribute to the Chinese learners' differences in their ability to comprehend the relative clause sentences, the different amount of Chinese learners' formal schooling on comprehension seems to be an interesting issue. An interesting point is that the more-exposed Chinese learners outperformed the native English speakers, displaying slight advantages in comprehension scores, whereas the least-exposed learners did show a considerable drop. It seems that there may be a kind of threshold level of exposure to explicit knowledge (i.e. English grammar rules) that ensures comprehension, and that once that threshold level has been reached, there are few benefits from further exposure. We might assume that further exposure may be of benefit to implicit knowledge. Indeed, the fact that the more-exposed Chinese learners have better accuracy scores than those of less-exposed Chinese learners in comprehending the English sentences might be taken as support for this position. However, the conclusions regarding the role of implicit knowledge in comprehension need to be further investigated.

\section{Conclusion}

The study investigated the exposure-related differences in comprehending two types of $w h$-related English relative clause sentences and one typical complex $w h$-movement sentence. It indicates that reduced response times relative to sentences with less amount of exposure, and large amount of formal exposure to syntactic structure in a sentence were beneficial in increasing comprehension accuracy. As the study is employed only wh-movement related English sentences, it is cautious that the potential utility of exposure-related meaning activation to reduce the response times and increase comprehension accuracy during L2 sentence processing and thereby facilitate the learning of a broader range of $\mathrm{L} 2$ comprehension skills.

\section{References}

Bock, J. K. (1986). "Syntactic persistence in language production". Cognitive Psychology, 18, 355-387. http://dx.doi.org/10.1016/0010-0285(86)90004-6

Chipere, N. (2003). Understanding Complex Sentences: Native Speaker Variations in Syntactic Competence. Palgrave, Basingstoke. http://dx.doi.org/10.1057/9780230005884

Chomsky, N. (1965). Aspects of the Theory of Syntax. Cambridge, MA: MIT Press.

Clahsen, H., \& Felser, C. (2006). "Grammatical processing in first and second language Learners". Applied Psycholinguistics, 27, 3-42. http://dx.doi.org/10.1017/S0142716406060024

Cuetos, F., Mitchell, D. C., \& Corley, M. M. B. (1996). "Parsing in different language". In M. Carreiras., \& J. E. Garcia-Albea et al. (eds.). Language Processing in Spanish. Mahwah, NJ: Erlbaum. 145-187.

Dabrowska, E. (1997). "The LAD goes to school: a cautionary tale for nativists", Linguistics, 35, 735-766. http://dx.doi.org/10.1515/ling.1997.35.4.735

Felser. C., \& Roberts. L. (2007). "Processing wh-dependencies in a second language: a cross-modal priming study". Second Language Research, 23(1), 9-36. http://dx.doi.org/10.1177/0267658307071600

Frenck-Mestre, C. (2002). "An on-line look at sentence processing in the L2”. In R. R. Heredia.,\& J. Altarriba (eds.). Bilingual Sentence Processing. Amsterdam, Elsevier. 217-236.

Hawkins, J. A. (1994). A Performance Theory of Order and Constituency. Cambridge: Cambridge University Press.

Hernandez, A., Bates, E., \& Avila, L. X. (1996). "Processing across the language boundary: a cross modal priming 
study of Spanish-English bilinguals". Journal of Experimental Psychology: Learning, Memory, \& Cognition, 22, 846-864. http://dx.doi.org/10.1037/0278-7393.22.4.846 PMid:8708603

Hopp, H. (2006). "Syntactic features and reanalysis in near-native processing". Second Language Research, 22(3), 369-397. http://dx.doi.org/10.1191/0267658306sr272oa

Juffs, A. (2006). "Grammar and parsing and a transition theory". Applied Psycholinguistics, 27, 69-91. http://dx.doi.org/10.1017/S0142716406060115

Lee, Jin-Hwa. (2009). "A subject-object asymmetry in the comprehension of wh-questions by Korean learners of English". Applied Linguistics, 31/1: 136-155. http://dx.doi.org/10.1093/applin/amp015

Loebell, H., \& Bock, K. (2003). "Structural priming across languages". Linguistics, 41, 791-824. http://dx.doi.org/10.1515/ling.2003.026

Luka, B. J. \& Barsalou, L. W. (2005). "Structural facilitation: Mere exposure effects for grammatical acceptability as evidence for syntactic priming in comprehension". Journal of Memory \& Language, 52(3), 436-459. http://dx.doi.org/10.1016/j.jml.2005.01.013

McDonough, K., \& Mackey, A. (2008). "Syntactic priming and ESL question development". Studies in Second Language Acquisition, 30, 31-47. http://dx.doi.org/10.1017/S0272263108080029

Mitchell, D. C., Cuetos, F., Corley, M.B., \& Brysbaert, M. (1995). "Exposure-based models of human parsing: evidence for the use of coarse-grained nonlexical statistical records". Journal of Psycholinguistic Research, 24, 469-488. http://dx.doi.org/10.1007/BF02143162

Pickering, M. J., \& Branigan, H. P. (1999). "Syntactic priming in language production". Trends in Cognitive Sciences, 3(4), 136-141. http://dx.doi.org/10.1016/S1364-6613(99)01293-0

Ren, Hulin, (2009) “Working memory and Chinese learners' processing of complex English sentences". The Proceedings of LAEL (2009), Volume 3, UK.

Seidenberg, M. S., \& MacDonald, M. C. (1999). "A probabilistic constraints approach to language acquisition and processing”. Cognitive Science, 23(4), 569-588. http://dx.doi.org/10.1207/s15516709cog2304_8

Shin Jeong Ah and Christianson Kiel. (2012). Structural priming and second language learning. Language Learning 62 (3): 931-964. http://dx.doi.org/10.1111/j.1467-9922.2011.00657.x

\section{Notes}

Note 1. McDonough and Mackey assume that there is difference between exact repetition of a string of words and repetition of the syntactic structure with (some) different words, but in my study I make no strict distinction between the two, and allow for slight variations in the subjects' choice of words.

Note 2. Here I use a special kind of exposure to English, i.e. the artificial classroom exposure to English, which is different from the usual meaning of exposure such as immersion or a natural setting. The reason for this is that this kind of exposure is the most common and often only way to get exposed to English for Chinese learners of English as a L2.

Note 3. Recall that Q1 receives 5 points, Q2, 3 points and Q3 and Q4, 1 point each.

Note 4. In these pilot studies it turned out that $1000 \mathrm{~ms}$ was the maximum response times of the slowest learners. 